\title{
Bullying and Cyberbullying in Spain and Poland, and Their Relation to Social, Emotional and Moral Competencies
}

\author{
Vicente J. Llorent ${ }^{1}$ (D) Adriana Diaz-Chaves ${ }^{1} \cdot$ Izabela Zych $^{1} \cdot$ Estera Twardowska-Staszek $^{2}$. \\ Inmaculada Marín-López ${ }^{1}$
}

Accepted: 22 July 2021 / Published online: 27 August 2021

(c) The Author(s) 2021

\begin{abstract}
Bullying and cyberbullying have been intensively studied in many countries, and research on the topic has been fruitful. Nevertheless, it is still necessary to advance knowledge on bullying and cyberbullying in many geographical areas and to discover their risk and protective factors. The objective of this study was to describe and compare the involvement in different bullying and cyberbullying roles in Spain and Poland, identifying risk and protective factors such as moral disengagement, social and emotional competencies, moral emotions and empathy. This study was carried out with a sample of 2535 primary and secondary school students from Spain and Poland. More bullying and cyberbullying involvement were found in Poland in comparison with Spain. Different moral disengagement mechanisms were found to be risk factors for involvement in bullying and cyberbullying in both countries. Low moral emotions were a risk factor for bullying and cyberbullying perpetration in Spain and Poland. Different social and emotional competencies were protective against bullying and cyberbullying in both countries. These results suggest the need to design and implement more programs to promote social, emotional and moral competencies in Spain and Poland to protect children against bullying and cyberbullying.
\end{abstract}

Keywords Bullying $\cdot$ Cyberbullying $\cdot$ Social and emotional competencies $\cdot$ Moral disengagement $\cdot$ Moral emotions · Empathy $\cdot$ Spain $\cdot$ Poland

\section{Introduction}

Bullying is a long-term and frequent aggressive behavior that takes place in a peer group. It is an intentional act of violence with an imbalance of power between a perpetrator and a victim who cannot defend himself or herself easily (Ortega-Ruiz, 2010; Smith et al., 2008). Nowadays, bullying occurs in schools and outside of the physical space, in a rapidly developing context of electronic devices and the Internet (Mora-Merchan et al., 2010). Therefore, cyberbullying is a form of bullying perpetrated through electronic devices when some students send hostile and aggressive messages, post harmful photos or videos, victimizing other students (Ortega-Ruiz et al., 2016).

\section{Izabela Zych}

izych@uco.es

1 University of Cordoba, Cordoba, Spain

2 Akademia Ignatianum in Cracow, Kraków, Poland
Bullying and cyberbullying exist worldwide, and they have some severe consequences for individuals and societies such as serious public health problems (Craig et al., 2009), anxiety, depression (Doumas \& Midgett, 2020; Ttofi et al., 2011), withdrawn behavior (Shakoor et al., 2011), psychosis (Arseneault et al., 2011), suicide ideation and suicide attempts (Van Geel et al., 2014), among others. Although past research findings were inconsistent, most studies showed a steady age-related decrease in bullying, especially in victimization, which is frequently explained by more precise definitions of bullying in older children (Monks \& Smith, 2006), or because they could become less vulnerable in middle childhood (Troop-Gordon, 2017). Most of the studies show that prevalence rates of cyberbullying increase from childhood to mid-adolescence and then decrease (Zych $\&$ Farrington, 2021). Thus, there is a developmental change in bullying and cyberbullying, but both are present already in primary school.

Given the severe consequences of bullying, research on the topic has been very fruitful in different geographic areas. Nevertheless, comparative studies focused on its risk and 
protective factors are still needed. Comparative studies are especially important because they make it possible to discover if findings can be generalized across contexts. Robust risk and protective factors that hold across contexts can be especially helpful to explain the mechanisms of bullying and cyberbullying.

\section{Bullying and Cyberbullying in Spain and Poland}

In Spain, a study conducted by Romera et al. (2017) found that around $30 \%$ of students reported bullying victimization, $2.6 \%$ reported bullying perpetration and $15 \%$ reported being a bully/victim in primary education. In secondary education, they reported $20 \%$ of victims, $6 \%$ of perpetrators and $17 \%$ of bully/victims. Eslea et al. (2004) found higher prevalence rates of perpetration and bully/victims in Spain in comparison with China, England, Ireland, Italy, Japan and Portugal. Nevertheless, a later study comparing Spain, the United Kingdom, and Italy showed that Spain had the lowest prevalence rates of victimization, perpetration and bully/victims (Ortega et al., 2012).

In Poland, Zych et al. (2017) found that, in a sample of about 900 adolescents, victimization of any type was reported by $18.7 \%$ of the participants, perpetration was reported by $13.1 \%$ of the participants and being a bully/victim was reported by $44.1 \%$. Another study conducted with Polish primary and secondary education students (Twardowska-Staszek et al., 2018) found that $6.5 \%$ reported perpetration, $31 \%$ victimization and $33 \%$ being a bully/victim. Compared to research using the same instrument in other countries such as Spain (Romera et al., 2017) and Colombia (Herrera-López et al., 2017), prevalence rates of bullying in Poland were higher.

Regarding cyberbullying, a systematic review conducted by Zych et al. (2016) including 21 studies on cyberbullying in Spain published since 2010 found a median cybervictimization prevalence of $26.65 \%$ and a median cyberperpetration prevalence of $24.64 \%$. Most of the studies were conducted with adolescents. A study that compared cyberbullying prevalence rates in eight European countries (Sorrentino et al., 2019) showed that the prevalence rates of cyberbullying perpetration and victimization in Spain were among the lowest in Europe. Prevalence rates of cyberperpetration and cybervictimization in Poland were also low compared to other countries, but higher than in Spain.

A study conducted by Twardowska-Staszek et al. (2018) in Poland found that 5.2\% of students reported cyberperpetration, $12.9 \%$ reported cybervictimization and $15.2 \%$ reported being cyberbully/victims. Del Rey et al. (2015) conducted a study with adolescents from Poland, Spain, Italy, the UK, Germany and Greece and found that $6.11 \%$ of students were cybervictims, $6.77 \%$ were cyberperpetrators, and $4 \%$ were cyberbully/victims. Poland had higher prevalence rates of cyberbullying than Spain, the UK and Germany in all the cyberbullying roles, but lower than Italy and Greece.

There are several anti-bullying and anti-cyberbullying programs in Spain, but the number of interventions in Poland is lower and more programs are needed (Gaffney et al., 2019b; Ttofi \& Farrington, 2011). These programs should be based on robust risk and protective factors, and factors related to social, emotional, and moral competencies still need to be thoroughly studied. Comparing Spain and Poland can be especially interesting because these two countries have different research and intervention trajectories regarding bullying and cyberbullying. With a high number of antibullying and anti-cyberbullying programs, many focused on promoting social, emotional and moral competencies in Spain (Romera et al., 2017), Spanish schools are a different context from Polish schools. According to Hofstede's index (https://www.hofstede-insights.com/), Poland and Spain are also culturally different. Poland is more an individualist country that scores high on masculinity whereas Spain is a collectivist country and score lower on masculinity. Thus, comparing Spain and Poland, countries with different research trajectories and cultures, is especially useful to understand if findings about bullying and cyberbullying are generalizable across different contexts.

Thus, research on bullying and cyberbullying has advanced significantly in different countries, but the number of studies in some geographic areas is still low. It is still necessary to advance knowledge about bullying in Poland and Spain. Moreover, the number of comparative studies is low, especially including different risk and protective factors.

\section{Risk and Protective Factors for Bullying and Cyberbullying}

Different studies focused on risk and protective factors for bullying and cyberbullying in different countries (Gaffney et al., 2019a, 2019b and 2019c; Kowalski et al., 2014; Zych et al., 2019a, 2019b). However, most of these studies have been conducted separately. Many risk and protective factors have been studied independently in relation to bullying and cyberbullying. Nevertheless, it is still necessary to include different risk and protective factors in the same study to understand which factors are uniquely related to bullying and cyberbullying in two different countries and cultures.

Given that bullying and cyberbullying were described as immoral behaviors (Ortega-Ruiz \& Monks, 2006), different studies focused on the relation between bullying and moral disengagement (Perren \& Gutzwiller, 2012). Moral disengagement is defined as cognitive mechanisms used 
to disconnect people's moral standards to justify immoral actions (Bandura et al., 1996). Bandura (2002) described different moral disengagement mechanisms including moral justification, advantageous comparison, euphemistic language, distortion of consequences, dehumanization, attribution of blame to the victim, displacement, and diffusion of responsibility. Research studies found that moral disengagement is related to more bullying perpetration. Gini et al. (2014), in a meta-analysis that included 27 studies from countries such as Spain, Italy, Japan, Australia, the United States, Canada, Denmark, Switzerland, the United Kingdom, China, Samoa and India, related to moral disengagement and aggressive behaviors in children and adolescents among the 8 and 18 years of age, indicated that low moral commitment was directly related to aggressive behavior, bullying and cyberbullying. A study conducted with adolescents in Poland found that the mechanisms of moral disengagement were related to greater bullying perpetration (Zych \& Llorent, 2019). Moral emotions, on the other hand, have been found to be protective against antisocial behaviors. Moral emotions are defined as adaptative emotions that appear after moral transgressions and stimulate desirable moral actions (Ortega-Ruiz et al., 2002). A study carried out with 12- to 19-year-old adolescents found that perpetrators reported a low level of moral emotions (Perren \& Gutzwiller, 2012).

Social and emotional competencies have also been studied in relation to bullying and cyberbullying. Social and emotional competencies are defined as knowledge, skills and abilities used to perform prosocial behaviors in different social contexts (Mikulic et al., 2015; Saarni, 1999). A study with children and adolescents in Israel (Eden et al., 2016) found that students with high social and emotional skills were less involved in bullying and cyberbullying. According to a study carried out in Spain with a representative sample of adolescents, perpetrators and bully/victims were found to have a low level of social and emotional competencies (Zych et al., 2018). Nevertheless, some researchers suggested that perpetrators can also be socially skillful manipulators with high social skills (Sutton et al., 1999).

Empathy, defined as a cognitive ability to understand other people's feelings and an affective ability to share other people's emotions (Jolliffe \& Farrington, 2006) is another variable studied in relation to bullying and cyberbullying. In a meta-analysis of 53 empirical studies, Zych et al. (2019a, 2019b) found that bullies and bully/victims scored low on empathy, and the relation between empathy and victimization was non-significant. A meta-analysis of 25 studies about cyberbullying showed that cyberbullies scored low on empathy while cybervictims seemed to score high on empathy, although with inconclusive results (Zych et al., 2019a, 2019b). In a study with a sample of primary and secondary education students in Italy, Caravita et al. (2009) found that perpetrators scored high on cognitive empathy and low on affective empathy. Similar results were found for bully/victims in New Zealand with a sample of 8- to 13-year-old children (Raskauskas et al., 2010). Caravita et al. (2009) found high empathy in victims of bullying, and Kokkinos and Kiprits (2012) did not find a significant relation between empathy and victimization.

\section{Current Study}

Different research studies focused on moral disengagement, social and emotional competencies, moral emotions and empathy in relation to bullying. Nevertheless, most of these studies analyzed these variables separately, without including them in one comprehensive study. Integrating these variables in one study makes it possible to discover which social, emotional and moral competencies are unique predictors of different bullying and cyberbullying roles. This will shed more light on specific competencies that need to be promoted to decrease bullying and cyberbullying.

Thus, the current study includes two different countries, Spain and Poland. Comparing these two countries is especially interesting as they represent two different cultures and educational trajectories regarding bullying and cyberbullying. Most of the studies were conducted in one geographic area only, and comparative research, including different geographic areas in the same study, is crucial to test the generalizability of the results, focusing on risk and protective factors.

The objective of the study was to compare Spain and Poland regarding bullying, cyberbullying, and their risk and protective factors. Another objective was to discover the relation between social and emotional competencies, moral emotions, empathy, and moral disengagement with different bullying and cyberbullying roles, including victims, perpetrators and bully/victims. Direct and unique relations among these variables were studied and compared in Polish and Spanish children and adolescents. It was hypothesized that i. prevalence rates of bullying and cyberbullying in Spain are lower than in Poland, ii. prevalence rates of bullying are higher in primary education and prevalence rates of cyberbullying are higher in secondary education, iii. students with high social, emotional and moral competencies are less involved in bullying and cyberbullying than the students with low social, emotional and moral competencies, and iv. Students with high scores in moral disengagement are more involved in bullying and cyberbullying than the students with low scores in moral disengagement. Differences in risk and protective factors for bullying and cyberbullying between the studied countries were tested, and this part of the study was exploratory in nature. 


\section{Method}

\section{Participants}

This study included 2535 participants enrolled in primary and secondary education schools in Spain $(n=1483)$ and Poland $(n=1052)$. Participants were selected through convenience sampling. They were between 9 and 16 years old $(M=12.62, \mathrm{SD}=2.09)$, with $50.5 \%$ of females and $48.5 \%$ of males ( $1 \%$ did not disclose their gender). The Spanish subsample was enrolled in 8 public and private schools in Cordoba and Sevilla, $40.3 \%$ were enrolled in primary education (from 3rd to 6th grade) and $59.7 \%$ in secondary education (from 1 st to 4 th grade). In the Spanish sample, $47.8 \%$ were females and $51.7 \%$ were males, aged $M=12.68$ years $(\mathrm{SD}=2.17)$. The Polish subsample was enrolled in 6 schools located in Lesser Poland, $42.5 \%$ in primary education (from 3rd to 6th grade) and 57.5\% in secondary education (from 1 st to 3 rd grade). In the Polish sample, $54.4 \%$ were females and $44.9 \%$ were males, aged $M=12.53$ years $(\mathrm{SD}=1.98)$. All the participants were enrolled in schools with standard characteristics for the studied regions which were similar to the population of each country in terms of ethnic-cultural and socioeconomic background.

\section{Design and Procedure}

This was an ex-post-facto cross-sectional study conducted with a survey. It was approved by the University of BLINDED Ethics Committee. It followed all the national and international ethical standards, including personal data protection legislation and the Helsinki Declaration.

Participants were selected by convenience based on the availability of the sample. The researchers had the previous contact with the schools through several previous investigations in both countries. First, head-teachers were contacted and asked to collaborate. School boards approved the participation in the study, and family authorizations were obtained. Data collection was done through a pen and paper questionnaire administered in Spanish in Spain and in Polish in Poland. The questionnaires were originally developed in Spanish, translated into Polish by a native Polish speaker and back-translated by a professional translation service. Confirmatory factor analyses were performed in both Spain and Poland to confirm the psychometric properties of the questionnaires.

Participation was voluntary and anonymous. Students were informed about the project and had the right to withdraw from the study at any moment. Questionnaires were administered during regular classroom hours in around $45 \mathrm{~min}$ (the youngest students usually needed more time than the oldest students) in June 2017 in Spain and in September and October 2017 in Poland. Students were supervised by the researchers who handed in and collected the questionnaires without any intervention from the teachers.

\section{Instruments}

\section{Bullying and Cyberbullying}

Involvement in bullying was measured with the European Bullying Intervention Project Questionnaire, validated with a sample of secondary students between 12 and 19 years old (EBIPQ; Ortega-Ruiz et al., 2016), and validated in Poland with students between 9 and 16 years old (Twardowska-Staszek et al., 2018). This questionnaire includes 14-items answered on a five-point Likert scale ranging from 1 (no) to 5 (yes, more than once a week). There are seven items focused on victimization (Spain: $\alpha=0.85$; Poland: $\alpha=0.81$; e.g., "Someone has hit me, kicked me or pushed me") and seven items focused on perpetration (Spain: $\alpha=0.79$; Poland: $\alpha=0.91$; e.g., "I have insulted and said bad words to someone"). A confirmatory factor analysis of the questionnaire showed an adequate fit of the current data to the original two-factor structure in Spain (S/B $\chi^{2}=558.0531, \mathrm{~d} f=76, p<0.001$, $\mathrm{NFI}=0.95, \mathrm{NNFI}=0.94, \mathrm{CFI}=0.95, \mathrm{RMSEA}=0.068$, $90 \% \mathrm{CI}=0.062-0.073)$ and Poland (S/B $\chi^{2}=796.23$, $\mathrm{d} f=76, p<0.001, \mathrm{NFI}=0.94, \mathrm{NNFI}=0.93, \mathrm{CFI}=0.94$, RMSEA $=0.09$ ).

The European Cyberbullying Intervention Project Questionnaire, validated with a sample of secondary students between 11 and 23 years old (ECIPQ, OrtegaRuiz et al., 2016), and validated in Poland with students between 9 and 16 years old (Twardowska-Staszek et al., 2018) includes 22 questions, 11 focused on cybervictimization (Spain: $\alpha=0.83$; Poland: $\alpha=0.97$; e.g., someone has posted embarrassing photographs or videos of me on the Internet) and 11 focused on cyberperpetration (Spain: $\alpha=0.81$; Poland: $\alpha=0.93$; e.g., I have posted embarrassing photographs or videos of someone on the Internet). Items are answered on a five-point Likert scale ranging from 1 (no) to 5 (yes, more than once a week). A confirmatory factor analysis showed a good fit of the current data to this factor structure in Spain $\left(\mathrm{S} / \mathrm{B} \chi^{2}=842.2489\right.$, $d f=208, p<0.001, \mathrm{NFI}=0.97, \mathrm{NNFI}=0.98, \mathrm{CFI}=0.98$, RMSEA $=0.046,90 \% \mathrm{CI}=0.043-0.050)$ and Poland (S/B $\chi^{2}=981.92, \mathrm{~d} f=208, p<0.001, \mathrm{NFI}=0.98, \mathrm{NNFI}=0.98$, $\mathrm{CFI}=0.98, \mathrm{RMSEA}=0.06$ ). 


\section{Moral Disengagement}

Moral disengagement was measured with Moral Disengagement Questionnaire validated by Bandura et al. (1996), with a sample of students between 10 and 15 years old. This questionnaire was shortened and excluded items that were difficult to understand for primary education students. The questionnaire included 19 items responded on a five-point Likert scale ranging from 1 (totally disagree) to 5 (totally agree). The questionnaire showed an excellent reliability (Spain: total $\alpha=0.85$; Poland: total $\alpha=0.96$ ). It included three subscales (based on Bandura et al., 1996) such as dehumanization and blaming others with seven items (Spain: $\alpha=0.67$; Poland: $\alpha=0.82$; e.g., "Some people deserve to be treated as animals"), minimizing consequences with four items (Spain: $\alpha=0.51$; Poland: $\alpha=0.74$; e.g., "It is fine to say little lies because actually it does not hurt"), and reconstruing moral transgressions with eight items (Spain: $\alpha=0.74$; Poland: $\alpha=0.83$ e.g., "It is fine fight to protect your friends"). A confirmatory factor analysis showed an adequate fit of the current data to the three-factor structure in Spain (S/B $\chi^{2}$ $=355.5691, d f=149, p<0.00, \mathrm{NFI}=0.93, \mathrm{NNFI}=0.95$, $\mathrm{CFI}=0.96$, RMSEA $=0.051,90 \% \mathrm{CI}=0.044-0.058$ ) and Poland (S/B $\chi^{2}=664.4819, \mathrm{~d} f=149, p<0.001$, $\mathrm{NFI}=0.97, \mathrm{NNFI}=0.97, \mathrm{CFI}=0.98, \mathrm{RMSEA}=0.085,90 \%$ $\mathrm{CI}=0.079-0.092)$.

\section{Social and Emotional Competencies}

Social and Emotional Competencies Questionnaire (SECQ; Zych et al., 2018), originally validated with a sample of students between 11 and 19 years old, was used to measure different social and emotional competencies,. In the current study, the questionnaire showed a good reliability (Spain: $\alpha=0.79$; Poland: $\alpha=0.90$ ). The questionnaire includes 16 items answered on a five-point Likert scale ranging from 1 (totally disagree) to 5 (totally agree), with four subscales: self-awareness (Spain: $\alpha=0.60$; Poland: $\alpha=0.78$; e.g., "I am aware of the thoughts that influence my emotions"), self-management and motivation (Spain: $\alpha=0.61$ : Poland: $\alpha=0.77$; e.g., "I know how to motivate myself"), social awareness and prosocial behavior (Spain: $\alpha=0.64$; Poland: $\alpha=0.79$; e.g., "I pay attention to the needs of others"), and responsible decision making (Spain: $\alpha=0.65$; Poland: $\alpha=0.78$; e.g., "I make decisions analyzing carefully possible consequences"). A confirmatory factor analysis showed an adequate fit of the current data to the four-factor model in Spain (S/B $\chi^{2}=221.635 ; \mathrm{d} f=98 ; p<0.001$; $\mathrm{NFI}=0.96 ; \mathrm{NNFI}=0.97$; $\mathrm{CFI}=0.98 ; \mathrm{RMSEA}=0.031$; $90 \% \mathrm{CI}=0.026-0.036)$ and Poland $\left(\mathrm{S} / \mathrm{B} \chi^{2}=291.1784\right.$; $\mathrm{d} f=98 ; p<0.001 ; \mathrm{NFI}=0.98 ; \mathrm{NNFI}=0.98 ; \mathrm{CFI}=0.99$; RMSEA $=0.047 ; 90 \% \mathrm{CI}=0.041-0.053)$.

\section{Moral Emotions}

Moral emotions were measured through the Moral Emotions Scale validated, with a sample of students between 9 and 19 years old by Álamo et al. (2020). This is a five-item scale describing moral emotions (e.g., feeling guilty after hurting a classmate), with a good reliability (Spain: $\alpha=0.68$; Poland: $\alpha=0.82$ ), answered on a five-point Likert scale ranging from 1 (totally disagree) to 5 (totally agree). A confirmatory factor analysis showed an adequate fit in Spain (S/B $\chi^{2}=$ $13.86 ; \mathrm{d} f=5 ; p<0.05 ; \mathrm{NFI}=0.99 ; \mathrm{NNFI}=0.99 ; \mathrm{CFI}=0.99$; RMSEA $=0.035 ; 90 \% \mathrm{CI}=0.014-0.058)$ and Poland (S/B $\chi^{2}=62.2857 ; \mathrm{d} f=5 ; p<0.001 ; \mathrm{NFI}=0.98 ; \mathrm{NNFI}=0.96$; $\mathrm{CFI}=0.98$; $\mathrm{RMSEA}=0.11 ; 90 \% \mathrm{CI}=0.08-0.13$ ).

\section{Empathy}

Empathy was measured with the Basic Empathy Scale, originally validated with 15 -year-old students (BES, Jolliffe \& Farrington, 2006), using a Polish and Spanish short version that was validated with students between 11 and 19 years old (Zych et al., 2021). The BES has 12 items $(\alpha=0.85$; items, e.g., feeling sad after staying with a friend who was sad), 6 focused on affective empathy (Spain: $\alpha=0.71$; Poland: $\alpha=0.76$; e.g., understanding friends' happiness) and 6 focused on cognitive empathy (Spain: $\alpha=0.74$; Poland: $\alpha=0.85$ ) answered on a five-point Likert scale ranging from 1 (totally disagree) to 5 (totally agree). A confirmatory factor analysis showed an adequate fit for the two-factor structure in Spain (S/B $\chi^{2}=232.19 ; d f=53, p<0.001$, $\mathrm{NFI}=0.97, \mathrm{NNFI}=0.97, \mathrm{CFI}=0.98, \mathrm{RMSEA}=0.050$, $90 \% \mathrm{CI}=0.044-0.057)$ and Poland $\left(\mathrm{S} / \mathrm{B} \chi^{2}=281.48\right.$, $\mathrm{d} f=53, p<0.001, \mathrm{CFI}=0.97, \mathrm{NFI}=0.96, \mathrm{NNFI}=0.96$, RMSEA $=0.07,90 \% \mathrm{CI}=0.0-0.08)$.

\section{Data Analysis}

Psychometric properties of the questionnaires for the current sample were analyzed first. Cronbach's alphas with PASW Statistics 25, and confirmatory factor analyses of all the questionnaires were run with EQS 6.2. To discover prevalence rates of bullying and cyberbullying in both countries, together with differences among groups, descriptive statistics were obtained, and comparisons among groups were performed through Student's t-tests, run in PASW Statistics 25. Effect sizes were obtained using Cohen's d calculated with Campbell Collaboration Calculator. The interpretation of effect sizes follows the rule of thumb criteria set out by Cohen (1988).

Pearson correlations were calculated for Spain and Poland to examine direct relations among all the study variables. Unique relations between the predictors and different bullying and cyberbullying roles were studied through 
multinomial logistic regression analyses, with the noninvolved student as the reference group. Bullying roles were obtained classifying students as pure victims if they responded at least once a month to any item focused on victimization and never or once or twice to any item on perpetration. Students were classified as bullies if they responded at least once a month to any item focused on perpetration and never or once or twice to any item on victimization. Bully/victims were the students who responded at least once a month to any item on both victimization and perpetration. Students who responded never or once or twice to all the items on perpetration and victimization were considered uninvolved. This was applied to both bullying and cyberbullying. These analyses were also run in PASW Statistics 25.

\section{Results}

Scores in each studied variable were compared between Spain and Poland. It was found that Polish students scored higher, with a small effect size, than the Spanish students in bullying victimization and perpetration, in primary education. Also, Polish students scored significantly higher, with a medium effect size, than the Spanish students, in cybervictimization and cyberperpetration in primary education, and bullying and cyberbullying, both victimization and perpetration, in secondary education.

Polish students also scored higher than the Spanish students in moral disengagement including all its subscales in primary education, with a medium effect size, and secondary education, with a large effect size. There were no significant differences between the countries in moral emotions in primary education, while in secondary education, the Spanish students had significantly higher scores than the Polish students, with a medium effect size.

Regarding the total scores in social and emotional competencies, Spanish students scored higher than the Polish students in secondary education while Polish students scored higher than the Spanish students in primary education, with a medium effect size. Taking into account different subscales, in primary education, Polish students scored higher, with a small effect size, than the Spanish students in selfawareness, social awareness and prosocial behavior, and responsible decision making. In secondary education, Spanish students scored higher, also with a small effect size, than the Polish students in self-management and motivation, and social awareness and prosocial behavior. Spanish students scored higher than the Polish students in cognitive empathy, and total empathy, only in secondary education, with a small effect size. Details are shown in Tables 1 and 2.

A correlation matrix showed that all the variables were correlated in the expected direction, both in Poland and in Spain. Thus, the next step of analyses required a more indepth study focused on the relations among these variables, though a multinomial logistic regression (Table 3 ).

Multinomial logistic regression analyses showed unique relations among different social, emotional and moral variables and bullying and cyberbullying roles in Spain (Table 4) and Poland (Table 5) with the non-involved student as the referent group. In Spain, being a victim of bullying was not

Table 1 Bullying, cyberbullying, moral disengagement, moral emotions, social and emotional competencies and empathy in primary education in Spain and Poland

\begin{tabular}{lcllll}
\hline & Spain M (SD) & Poland M (SD) & $\mathrm{t}$ & $p$ & $\mathrm{~d}(95 \% \mathrm{CI})$ \\
\hline Bullying victimization & $13.15(6.24)$ & $14.09(7.65)$ & -2.14 & .03 & $-0.14(-0.26,-0.01)$ \\
Bullying perpetration & $9.67(3.71)$ & $10.67(7.30)$ & -2.63 & .01 & $-0.18(-0.30,-0.06)$ \\
Cybervictimization & $12.11(2.73)$ & $17.17(19.12)$ & -5.55 & $<.01$ & $-0.40(-0.52,-0.27)$ \\
Cyberperpetration & $11.50(1.53)$ & $17.25(21.16)$ & -5.71 & $<.01$ & $-0.41(-0.54,-0.29)$ \\
Dehumanization and blaming others & $13.95(5.00)$ & $16.78(11.78)$ & -4.72 & $<.01$ & $-0.33(-0.45,-0.20)$ \\
Minimizing consequences & $6.59(2.81)$ & $9.04(7.12)$ & -6.89 & $<.01$ & $-0.47(-0.60,-0.35)$ \\
Reconstruing moral transgressions & $15.54(5.62)$ & $19.36(12.31)$ & -6.08 & $<.01$ & $-0.42(-0.54,-0.29)$ \\
Moral disengagement total & $36.07(11.36)$ & $45.18(30.41)$ & -5.99 & $<.01$ & $-0.41(-0.54,-0.28)$ \\
Moral Emotions & $21.99(3.16)$ & $21.67(3.95)$ & 1.40 & .14 & $0.09(-0.03,0.21)$ \\
Self-awareness & $16.46(2.66)$ & $17.00(2.97)$ & -3.02 & $<.01$ & $-0.19(-032,-0.07)$ \\
Self-management and motivation & $12.67(2.21)$ & $13.03(2.49)$ & -2.44 & .01 & $-0.15(-0.28,-0.03)$ \\
Social awareness and prosocial behavior & $24.55(3.42)$ & $25.71(3.47)$ & -5.35 & $<.01$ & $-0.34(-0.46,-0.21)$ \\
Responsible decision making & $10.95(2.58)$ & $11.91(2.80)$ & -5.67 & $<.01$ & $-0.36(-0.48,-0.23)$ \\
Social and emotional competencies total & $64.73(8.02)$ & $67.65(8.56)$ & -5.47 & $<.01$ & $-0.35(-0.48,-0.23)$ \\
Affective empathy & $20.67(5.43)$ & $21.05(7.31)$ & -0.90 & .37 & $-0.06(-0.18,0.06)$ \\
Cognitive empathy & $24.66(4.44)$ & $24.49(7.38)$ & 0.43 & .67 & $0.29(-0.10,0.15)$ \\
Empathy total & $45.42(8.42)$ & $45.53(13.73)$ & -0.15 & .88 & $-0.01(-0.14,0.12)$ \\
\hline
\end{tabular}


Table 2 Bullying, cyberbullying, moral disengagement, moral emotions, social and emotional competencies and empathy in secondary education in Spain and Poland

\begin{tabular}{|c|c|c|c|c|c|}
\hline & Spain M (SD) & Poland M (SD) & $\mathrm{t}$ & $p$ & $\mathrm{~d}(95 \% \mathrm{CI})$ \\
\hline Bullying victimization & $11.67(5.54)$ & $15.24(8.57)$ & 8.98 & $<.01$ & $-0.51(-0.62,-0.41)$ \\
\hline Bullying perpetration & $9.55(3.53)$ & $13.40(8.14)$ & -10.93 & $<.01$ & $-0.66(-0.76,-0.55)$ \\
\hline Cybervictimization & $13.24(4.39)$ & $17.02(11.26)$ & -7.84 & $<.01$ & $-0.47(-0.58,-0.37)$ \\
\hline Cyberperpetration & $12.39(3.23)$ & $15.46(10.49)$ & -6.96 & $<.01$ & $-0.43(-0.53,-0.32)$ \\
\hline Dehumanization and blaming others & $13.33(5.00)$ & $19.74(10.57)$ & -13.78 & $<.01$ & $-0.82(-0.93,-0.71)$ \\
\hline Minimizing consequences & $7.18(2.88)$ & $11.04(6.34)$ & -13.97 & $<.01$ & $-0.83(-0.94,-0.72)$ \\
\hline Reconstruing moral transgressions & $16.18(4.89)$ & $23.66(10.57)$ & -16.18 & $<.01$ & $-0.96(-1.07,-0.85)$ \\
\hline Moral disengagement total & $36.55(10.97)$ & $54.26(26.11)$ & -15.59 & $<.01$ & $-0.93(-1.04,-0.82)$ \\
\hline Moral Emotions & $21.30(3.35)$ & $19.11(5.39)$ & 8.85 & $<.01$ & $0.51(0.40,0.61)$ \\
\hline Self-awareness & $16.16(2.57)$ & $16.19(3.53)$ & -0.17 & .85 & $-0.01(-0.11,0.09)$ \\
\hline Self-management and motivation & $12.06(2.34)$ & $11.57(2.91)$ & 3.46 & $<.01$ & $0.19(0.09,0.29)$ \\
\hline Social awareness and prosocial behavior & $23.88(3.13)$ & $22.80(4.67)$ & 4.94 & $<.01$ & $0.28(0.18,0.39)$ \\
\hline Responsible decision making & $10.33(2.76)$ & $10.46(3.10)$ & -0.83 & .40 & $-0.04(-0.15,0.06)$ \\
\hline Social and emotional competencies total & $62.49(7.44)$ & $61.01(11.39)$ & 2.77 & $<.01$ & $0.16(0.05,0.26)$ \\
\hline Affective empathy & $19.13(5.54)$ & $18.78(6.16)$ & 1.15 & .25 & $0.06(-0.04,0.16)$ \\
\hline Cognitive empathy & $24.20(4.14)$ & $22.29(5.48)$ & 7.22 & $<.01$ & $0.40(0.30,0.51)$ \\
\hline Empathy total & $43.34(8.17)$ & $41.08(10.43)$ & 4.43 & $<.01$ & $0.25(0.14,0.35)$ \\
\hline
\end{tabular}

predicted by any of the studied variables. Being a cybervictim was predicted by being a secondary education student and high scores in dehumanization and blaming others. Being a bullying perpetrator was predicted by low moral emotions and high reconstruing moral transgressions. Being a cyberperpetrator was predicted by being a secondary education student, low moral emotions, high dehumanization and blaming others, and reconstruing moral transgression, together with low scores in minimizing consequences. Being a bully/victim was predicted by being a boy, low responsible decision making, and high reconstruing of moral transgressions. Being a cyberbully/victim was predicted by being a secondary education student, and scoring low on responsible decision making and low on moral emotions, and high on dehumanization and blaming others.

In Poland, being a victim of bullying was predicted by being in primary school, low social awareness and prosocial behavior, and low reconstruing moral transgressions. Being a cybervictim was predicted by being in secondary school, low social awareness and prosocial behavior, high affective empathy, high dehumanization and blaming others and low reconstruing moral transgressions. Being a bullying perpetrator was predicted by being in secondary school and low self-awareness, high self-management and motivation, low responsible decision making, and low affective empathy. Being a cyberperpetrator was predicted by being in secondary school, low responsible decision making, low moral emotions, low affective empathy, and high cognitive empathy. Being a bully/victim was related to being a girl, being in secondary school, high self-awareness, and low social awareness and prosocial behavior. Being a cyberbully/victim was predicted by being a secondary education student, low social awareness and prosocial behavior, low responsible decision making, high affective empathy, and low cognitive empathy.

\section{Discussion}

Bullying and cyberbullying are serious types of violent behavior among peers (Ortega-Ruiz et al., 2002), present around the world with no physical, contextual or cultural limits (Craig et al., 2009). Given the serious consequences of both bullying and cyberbullying, many research studies have been conducted to describe their nature and dynamics in different countries. Even though research focused on bullying and cyberbullying has been fruitful, they are still present and prevalent in schools around the world. There are also some pressing gaps in knowledge, as research on bullying and cyberbullying is not equally advanced among different geographic areas. Studies in countries such as Poland and Spain are still needed. Moreover, most of the studies focused on some predictors only, and the number of comparative studies that use a high number of predictors in the same analysis, making it possible to study unique relations among variables, is still low.

Thus, the objective of this study was to describe and compare the involvement in different bullying and cyberbullying roles in Spain and Poland, in primary and secondary education. In general, Poland was found to have a higher level of 


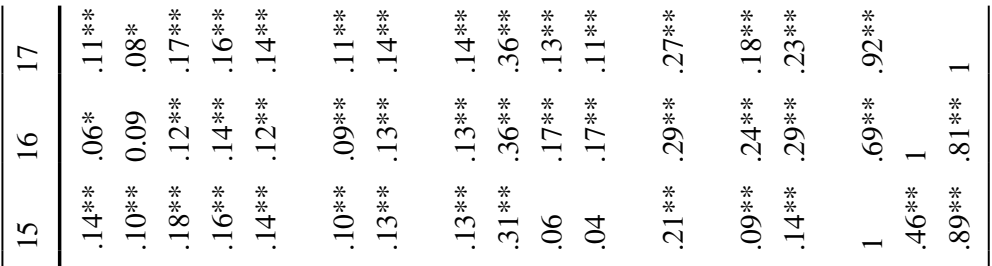

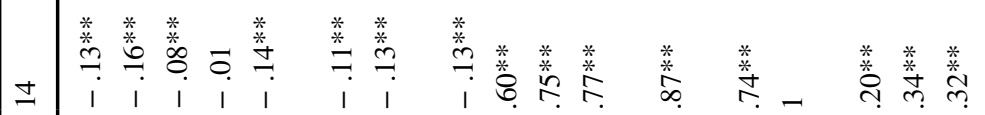

の

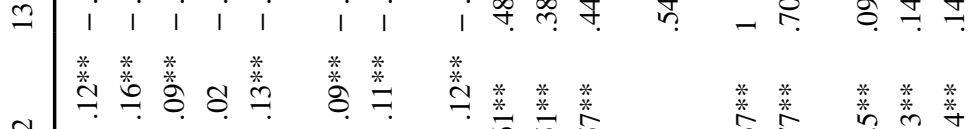

I i i i i i i

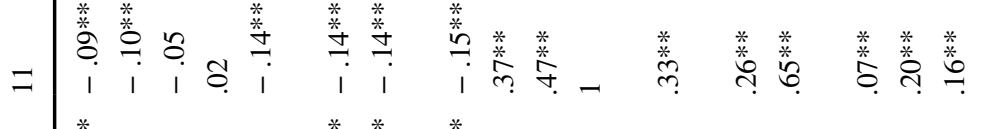

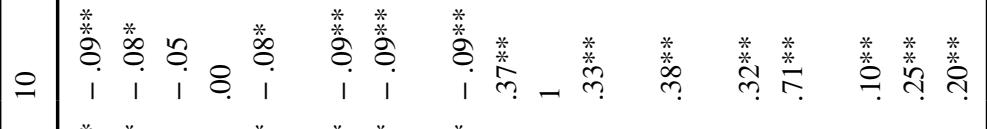

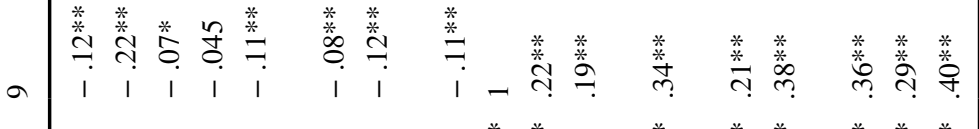

$\infty$ 菜

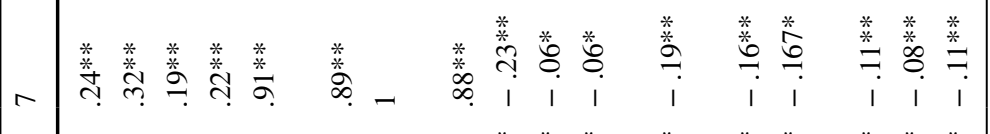

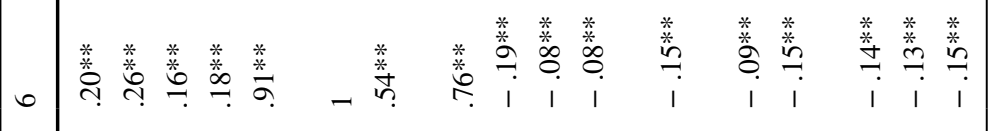

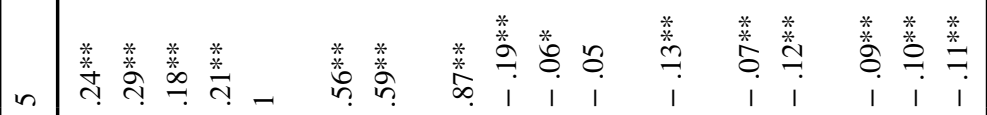

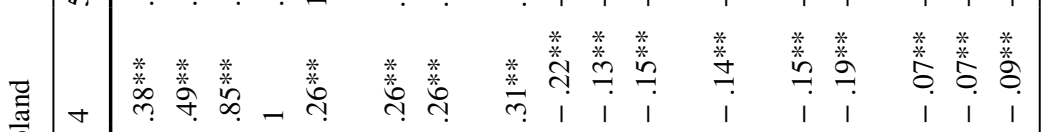

$\sigma$
$\dot{0}$
2
$*$
$*$

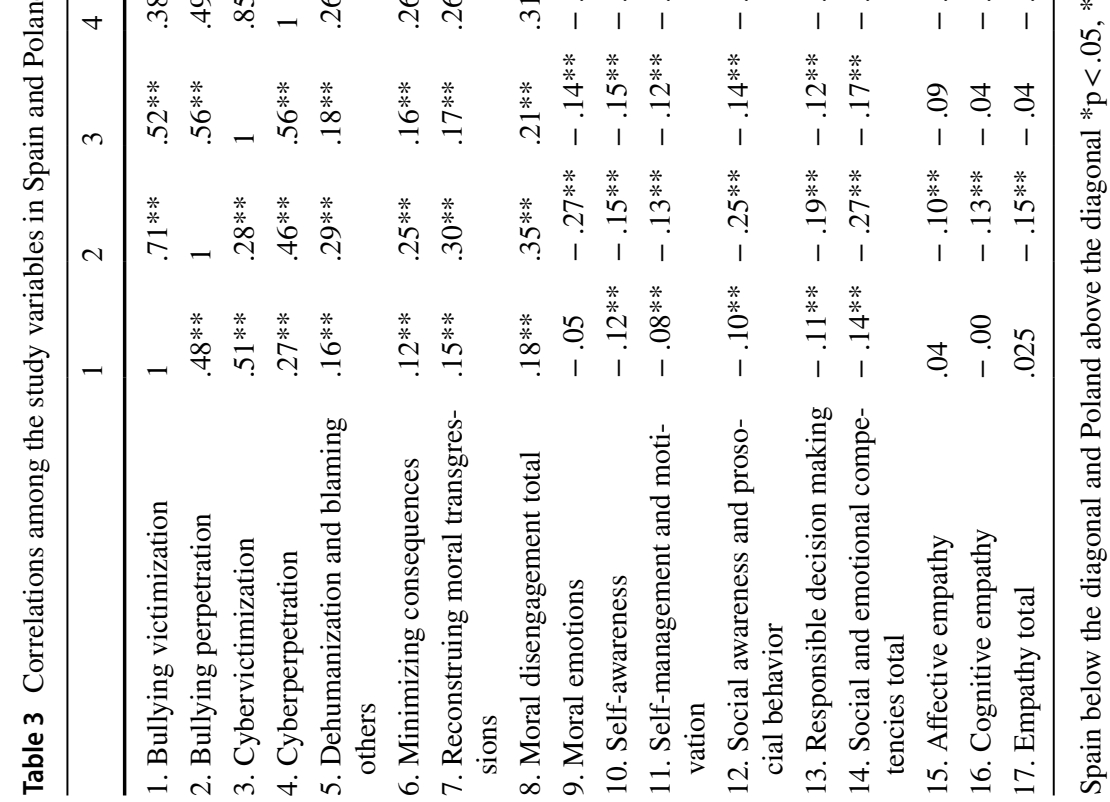


Table 4 Multinomial logistic regression showing predictors of different bullying and cyberbullying roles in Spain

\begin{tabular}{|c|c|c|c|c|c|c|}
\hline & $\begin{array}{l}\text { Victim } \\
(n=267)\end{array}$ & $\begin{array}{l}\text { Cybervictim } \\
(n=99)\end{array}$ & $\begin{array}{l}\text { Bully } \\
(n=44)\end{array}$ & $\begin{array}{l}\text { Cyberbully } \\
(n=34)\end{array}$ & $\begin{array}{l}\text { Bully/victim } \\
(n=195)\end{array}$ & $\begin{array}{l}\text { Cyberbully/victim } \\
(n=61)\end{array}$ \\
\hline & OR $(95 \% \mathrm{CI})$ & OR 95\%CI) & OR $(95 \% \mathrm{CI})$ & OR (95\%CI) & $\mathrm{OR}(95 \% \mathrm{CI})$ & OR $(95 \% \mathrm{CI})$ \\
\hline Sex (male) & $0.99(0.72-1.37)$ & $0.76(0.47-1.20)$ & $1.72(0.81-3.62)$ & $0.79(0.36-1.75)$ & $1.76(1.19-2.60) *$ & $0.89(0.47-1.68)$ \\
\hline $\begin{array}{l}\text { Level of education } \\
\text { (secondary) }\end{array}$ & $0.76(0.56-1.04)$ & $1.71(1.07-2.74) *$ & $1.40(0.66-2.95)$ & $3.20(1.34-7.64) *$ & $0.80(0.55-1.16)$ & $2.57(1.30-5.07) *$ \\
\hline Self-awareness & $0.97(0.91-1.04)$ & $0.94(0.86-1.03)$ & $1.01(0.89-1.16)$ & $1.01(0.87-1.17)$ & $0.97(0.90-1.05)$ & $0.90(0.81-1.00)$ \\
\hline $\begin{array}{l}\text { Self-management and } \\
\text { motivation }\end{array}$ & $0.95(0.89-1.03)$ & $0.97(0.88-1.07)$ & $0.89(0.78-1.02)$ & $1.05(0.89-1.24)$ & $0.93(0.86-1.01)$ & $0.93(0.82-1.04)$ \\
\hline $\begin{array}{l}\text { Social awareness and } \\
\text { prosocial behavior }\end{array}$ & $0.99(0.93-1.05)$ & $0.94(0.87-1.02)$ & $0.97(0.87-1.09)$ & $0.91(0.80-1.03)$ & $0.94(0.88-1.00)$ & $0.92(0.83-1.01)$ \\
\hline $\begin{array}{l}\text { Responsible decision } \\
\text { making }\end{array}$ & $0.99(0.93-1.06)$ & $1.01(0.92-1.10)$ & $0.98(0.86-1.11)$ & $0.95(0.83-1.09)$ & $0.90(0.84-0.96) *$ & $0.89(0.79-0.99) *$ \\
\hline Moral emotions & $0.98(0.93-1.04)$ & $1.02(0.95-1.11)$ & $0.85(0.77-0.95) *$ & $0.88(0.79-0.99) *$ & $0.94(0.88-1.00)$ & $0.91(0.83-0.99) *$ \\
\hline Affective empathy & $1.01(0.98-1.05)$ & $1.00(0.95-1.04)$ & $1.00(0.93-1.07)$ & $1.03(0.95-1.11)$ & $1.02(0.98-1.06)$ & $0.98(0.92-1.05)$ \\
\hline Cognitive empathy & $1.02(0.98-1.07)$ & $1.01(0.95-1.08)$ & $0.93(0.86-1.01)$ & $1.04(0.93-1.15)$ & $1.02(0.97-1.07)$ & $1.08(0.99-1.17)$ \\
\hline $\begin{array}{l}\text { Dehumanization and } \\
\text { blaming others }\end{array}$ & $1.03(0.99-1.07)$ & $1.07(1.01-1.13) *$ & $1.03(0.95-1.12)$ & $1.11(1.02-1.21) *$ & $1.04(0.99-1.08)$ & $1.08(1.01-1.16) *$ \\
\hline $\begin{array}{l}\text { Minimizing conse- } \\
\text { quences }\end{array}$ & $0.96(0.90-1.03)$ & $0.96(0.87-1.06)$ & $0.95(0.83-1.10)$ & $0.84(0.73-0.98) *$ & $0.98(0.91-1.05)$ & $1.02(0.91-1.14)$ \\
\hline $\begin{array}{l}\text { Reconstruing moral } \\
\text { transgressions }\end{array}$ & $1.03(0.99-1.07)$ & $1.02(0.97-1.08)$ & $1.09(1.01-1.18)^{*}$ & $1.14(1.05-1.23)^{*}$ & $1.09(1.05-1.14) *$ & $1.07(0.99-1.14)$ \\
\hline
\end{tabular}

Bullying: 534 students no involved and model fitness $\chi^{2}=176.70, d f=36, p<.001$, Nagelkerke $\mathrm{R}^{2}=.17$

Cyberbullying: 865 students no involved and model fitness $\chi^{2}=149.29, d f=36, p<.001$, Nagelkerke $\mathrm{R}^{2}=.18$

$* \mathrm{p}<.05$

involvement in all the bullying and cyberbullying roles, confirming the first hypothesis of this study. A relatively high level of bullying in Poland was also found in previous studies with secondary education students (Zych, et al., 2017b). Also, the level of social and emotional competencies, moral emotions, and empathy are generally lower in the Polish subsample, while moral disengagement was higher. A systematic review and meta-analysis of anti-bullying programs in schools (Gaffney et al., 2019a and b) showed that these programs are still needed in Poland. A systematic review and meta-analysis of programs against cyberbullying (Gaffney et al., 2019c) found that these programs are needed in Poland too. Thus, it is possible that this higher level of bullying and cyberbullying, higher risk factors and lower protective factors in Poland are related to an insufficient number of anti-bullying and anti-cyberbullying programs that should be increased at schools. Nevertheless, more research is needed to understand these differences, as it is also possible that bullying and cyberbullying are perceived differently in both countries or that consequences of bullying and cyberbullying differ between Poland and Spain.

Regarding risk and protective factors, there were some similarities, but also some differences between Spain and Poland. A close inspection of the odds rations across countries shows that many risk and protective factors across bullying and cyberbullying roles were similar, as indicated by overlapping confidence intervals. Thus, it is possible that some of the intervention programs that were found to be effective in Spain (see Gaffney et al., 2019a and 2019b) could also be effective in Poland, although more research is needed to confirm this. Regarding differences between the countries, the effect of being a secondary education student on the involvement in any cyberbullying role was much stronger in Poland. It is possible that children start to use electronic devices in Spain earlier than in Poland, so the difference between primary and secondary education is smaller, but again, future research needs to be conducted to discover these possible differences.

In Spain, face-to-face bullying victimization was not predicted by any of the studied variables. However, in Poland, there were unique predictors of face-to-face victimization such as being a student of primary education, low social awareness and prosocial behavior, and low reconstruing moral transgressions. It is possible that the promotion of these social and emotional competencies in Poland could decrease victimization, but more studies are needed to confirm this.

Being in secondary level of education and high dehumanization of the victim predicted cybervictimization both in Spain and Poland. Additionally, cybervictimization was 
Table 5 Multinomial logistic regression showing predictors of different bullying and cyberbullying roles in Poland

\begin{tabular}{|c|c|c|c|c|c|c|}
\hline & $\begin{array}{l}\text { Victim } \\
(n=271)\end{array}$ & $\begin{array}{l}\text { Cybervictim } \\
(n=96)\end{array}$ & $\begin{array}{l}\text { Bully } \\
(n=40)\end{array}$ & $\begin{array}{l}\text { Cyberbully } \\
(n=35)\end{array}$ & $\begin{array}{l}\text { Bully/victim } \\
(n=239)\end{array}$ & $\begin{array}{l}\text { Cyberbully/victim } \\
(n=89)\end{array}$ \\
\hline & OR $(95 \% \mathrm{CI})$ & OR $(95 \% \mathrm{CI})$ & OR $(95 \% \mathrm{CI})$ & OR (95\%CI) & OR $(95 \% \mathrm{CI})$ & OR (95\%CI) \\
\hline Sex (male) & $1.21(0.82-1.78)$ & $0.92(0.57-1.50)$ & $0.71(0.33-1.52)$ & $1.70(0.76-3.81)$ & $0.54(0.36-0.80)^{*}$ & $0.96(0.57-1.63)$ \\
\hline $\begin{array}{l}\text { Level of education } \\
\text { (secondary) }\end{array}$ & $0.52(0.35-0.78)^{*}$ & $4.84(2.79-8.39)^{*}$ & $2.70(1.15-6.36)^{*}$ & $6.78(2.46-18.67)^{*}$ & $2.09(1.37-3.20)^{*}$ & $9.25(4.46-19.20) *$ \\
\hline Self-awareness & $1.05(0.97-1.13)$ & $1.00(0.91-1.09)$ & $0.87(0.77-0.99)^{*}$ & $0.99(0.87-1.12)$ & $1.11(1.02-1.20)^{*}$ & $0.93(0.85-1.02)$ \\
\hline $\begin{array}{l}\text { Self-management } \\
\text { and motivation }\end{array}$ & $1.01(0.93-1.11)$ & $1.07(0.96-1.21)$ & $1.34(1.11-1.62)^{*}$ & $1.20(0.99-1.45)$ & $1.03(0.93-1.13)$ & $1.03(0.91-1.02)$ \\
\hline $\begin{array}{c}\text { Social awareness and } \\
\text { prosocial behavior }\end{array}$ & $0.90(0.84-0.97)^{*}$ & $0.90(0.83-0.98)^{*}$ & $0.97(0.85-1.11)$ & $1.07(0.94-1.21)$ & $0.89(0.83-0.96)^{*}$ & $0.89(0.81-0.98)^{*}$ \\
\hline $\begin{array}{l}\text { Responsible decision } \\
\text { making }\end{array}$ & $1.00(0.93-1.08)$ & $0.91(0.81-1.01)$ & $0.84(0.73-0.98)^{*}$ & $0.79(0.67-0.93) *$ & $0.93(0.86-1.01)$ & $0.88(0.79-0.99)^{*}$ \\
\hline Moral emotions & $1.03(0.98-1.09)$ & $1.02(0.96-1.09)$ & $0.97(0.88-1.06)$ & $0.87(0.80-0.95)^{*}$ & $0.95(0.90-1.00)$ & $1.03(0.96-1.10)$ \\
\hline Affective empathy & $1.01(0.97-1.05)$ & $1.07(1.01-1.13)^{*}$ & $0.91(0.84-0.98) *$ & $0.89(0.82-0.96)^{*}$ & $1.04(0.99-1.08)$ & $1.10(1.03-1.16)^{*}$ \\
\hline Cognitive empathy & $1.02(0.98-1.07)$ & $0.99(0.93-1.05)$ & $1.05(0.96-1.15)$ & $1.13(1.03-1.25)^{*}$ & $0.99(0.94-1.04)$ & $0.93(0.87-0.99)^{*}$ \\
\hline $\begin{array}{l}\text { Dehumanization and } \\
\text { blaming others }\end{array}$ & $1.05(0.99-1.11)$ & $1.09(1.02-1.16)^{*}$ & $0.98(0.88-1.09)$ & $1.08(0.97-1.20)$ & $1.04(0.98-1.10)$ & $1.06(0.98-1.14)$ \\
\hline $\begin{array}{l}\text { Minimizing conse- } \\
\text { quences }\end{array}$ & $1.02(0.94-1.10)$ & $0.95(0.86-1.05)$ & $0.96(0.82-1.12)$ & $0.99(0.84-1.16)$ & $0.96(0.89-1.05)$ & $0.91(0.82-1.02)$ \\
\hline $\begin{array}{l}\text { Reconstruing moral } \\
\text { transgressions }\end{array}$ & $0.93(0.89-0.98)^{*}$ & $0.94(0.88-1)$ & $1.07(0.98-1.18)$ & $0.97(0.88-1.06)$ & $1.00(0.95-1.05)$ & $1.03(.97-1.10)$ \\
\hline
\end{tabular}

Bullying: 251 students no involved and model fitness $\chi^{2}=228.70, \mathrm{~d} f=36, p<.001$, Nagelkerke $R^{2}=.27$

Cyberbullying: 578 students no involved and model fitness $\chi^{2}=252.55, \mathrm{~d} f=36, p<.001$, Nagelkerke $R^{2}=.33$

$* \mathrm{p}<.05$

predicted by low social awareness and prosocial behavior and high affective empathy in Poland, but not in Spain. It is possible that children in secondary education use the Internet more than the children in primary education, as suggested by previous studies (Heirman \& Walrave, 2008; Sticca et al., 2013), and are more exposed to victimization. It should also be considered that adolescents have more opportunities to interact through electronic devices in their own bedrooms (Law et al., 2010), and also through mobile devices (Sticca et al., 2013). Cybervictimization has serious short and long-term consequences (Kowalski et al., 2014). Among them, it has been found that victims assume their role and show low self-esteem (Cook et al., 2010) whereas perpetrators could perceive victims as less human. It is possible that, especially Polish children, need more training in social awareness and prosocial behavior which can potentially relate to a safer Internet use and less cybervictimization. Regarding high affective empathy in Polish cybervictims, this finding was also reported by other studies such as ta meta-analysis conducted by Zych et al., (2019a and 2019b), which included 25 studies from different countries. It is possible that children who suffer victimization tend to share other people's feelings more intensively as they know well what suffering means.

Low moral emotions and high reconstruing moral transgressions predicted face-to-face perpetration in Spain. In
Poland, perpetration was predicted by being a student of secondary education, low self-awareness, low responsible decision making, low affective empathy and high self-management and motivation. In Spain, being a student of secondary education, low moral emotions, high dehumanization and blaming others, low minimizing consequences and reconstruing moral transgressions predicted cyberperpetration. Being a student of secondary education, low responsible decision making, low moral emotions, low affective empathy and high cognitive empathy predicted cybervictimization in Poland. Thus, as described in different studies (Llorent et al., 2021; Romera et al., 2019), social, emotional and moral competencies could be crucial for bullying prevention. These results show that increasing those competencies and decreasing moral disengagement could be especially useful as they are potentially robust predictors (Zych \& Llorent, 2019) across contexts and cultures, but more studies are needed to confirm this.

Regarding being a bully/victim, several components of social, emotional and moral competencies were protecting factors in both Spain and Poland. Bully/victims were predicted by being a boy, and low responsible decision making in Spain. In Poland being a girl, being a secondary level student, and scoring low in self-awareness, and low social awareness and prosocial behavior predicted the bully/victim role. Gender difference between Poland and Spain in the 
bully/victim role could be related to differences in masculinity between the two countries, but more research is needed to understand this. Being a student of secondary education and scoring low in responsible decision making predicted the cyberbully/victim role in both Spain and Poland. Additionally, low moral emotions, and high dehumanization and blaming predicted being a cyberbully/victim in Spain, while in Poland low social awareness and prosocial behavior, high affective empathy and low cognitive empathy were risk factors for being a cyberbully/victim. Bully/victim role in bullying and cyberbullying seems more complex than other roles. Thus, moral education seems to be especially important for bully/victims and cyberbully/victims in both countries, as suggested by Romera et al. (2019). Also, social and emotional learning programs that showed to be effective against different problem behaviors (Durlak et al., 2011) could be especially beneficial. The complexity of this topic requires a holistic perspective from the schools involving curriculum and action planning (Llorent et al., 2021). Social, emotional and moral competencies expressed online should be taken into account to decrease cyberbullying (Marín-López et al., 2020).

The current study provides important results for policy and practice against bullying and cyberbullying in Poland and Spain. Nevertheless, it also has some limitations. Participants in both countries were selected through convenience sampling, and studies with representative samples should be conducted to confirm the results. Data are based on selfreports, and it would be useful to include other-reports in future studies. Risk and protective factors are studied on a theoretical basis, but longitudinal and experimental studies are needed to disentangle predictors from correlates and consequences.

Even with these limitations, the results can be useful for prevention and intervention in bullying and cyberbullying, and their implications for school mental health. Previous studies reported a direct and positive relation between involvement in bullying and cyberbullying and problems such as anxiety, depression (Doumas \& Midgett, 2020; Ttofi et al., 2011), comorbid depression and anxiety disorders (Yuchang et al., 2017), withdrawn behavior (Shakoor et al., 2011), self-esteem problems (Lösel \& Bender, 2011; Ozdemir \& Stattin, 2011), anticipation of failure (Ozdemir \& Stattin, 2011), psychosis (Arseneault et al., 2011), suicide ideation and suicide attempts (Van Geel et al., 2014).

Based on the current findings, it is important to put in practice policies against bullying and cyberbullying in both countries. Whole-school intervention programs against bullying and cyberbullying are conducted around the world, many promote social, emotional and moral competencies, and they were found to be effective in different geographic areas and cultures (Gaffney et al., 2019a, 2019c). Increasing the number of these programs could be especially important in Poland as Polish participants reported more bullying and cyberbullying than the Spanish participants. Based on our results, promoting social, emotional and moral competencies is also more needed in Poland, but it should be done in both countries. Given that there are different emerging antisocial behaviors online (Oksanen et al., 2021), and children involved in bullying and cyberbullying are also frequently involved in other antisocial behaviors such as theft, property damage, drug use, status offences and other types of violence (Nasaescu et al., 2020), holistic and comprehensive interventions are needed to decrease possible common underlying mechanisms of these behaviors. Social and emotional learning programs can be especially useful to decrease problem behaviors (Durlak et al., 2011), and given the relation between social, emotional and moral competencies, bullying and cyberbullying found in this study, they can be especially useful both in Poland and Spain. Tailored interventions that could promote protective factors related to social, emotional and moral competencies discovered in this study could be especially useful.

Funding Funding for open access charge: Universidad de Córdoba/ CBUA. Open Access funding provided thanks to the CRUE-CSIC agreement with Springer Nature.

Open Access This article is licensed under a Creative Commons Attribution 4.0 International License, which permits use, sharing, adaptation, distribution and reproduction in any medium or format, as long as you give appropriate credit to the original author(s) and the source, provide a link to the Creative Commons licence, and indicate if changes were made. The images or other third party material in this article are included in the article's Creative Commons licence, unless indicated otherwise in a credit line to the material. If material is not included in the article's Creative Commons licence and your intended use is not permitted by statutory regulation or exceeds the permitted use, you will need to obtain permission directly from the copyright holder. To view a copy of this licence, visit http://creativecommons.org/licenses/by/4.0/.

\section{References}

Álamo, M., Llorent, V. J., Nasaescu, E., \& Zych, I. (2020). Validación de la Escala de Emociones Morales en Adolescentes. En V. Llorent-Bedmar \& V. Cobano-Delgado. (Dir. y Ed.), Congreso Internacional de Transferencia de Conocimientos y Sensibilización Social "Islam y paz a través de voces musulmanas" (pp. 21-28). Sevilla, España.

Arseneault, L., Cannon, M., Fisher, H. L., Polanczyk, G., Moffitt, T. E., \& Caspi, A. (2011). Childhood trauma and children's emerging psychotic symptoms: A genetically sensitive longitudinal cohort study. American Journal of Psychiatry, 168, 65-72. https://doi. org/10.1176/appi.ajp.2010.10040567

Bandura, A. (2002). Selective moral disengagement in the exercise of moral agency. Journal of Moral Education, 31, 101-119. https:// doi.org/10.1080/0305724022014322

Bandura, A., Barbaranelli, C., Caprara, G., \& Pastorelli, C. (1996). Mechanisms of moral disengagement in the exercise of moral 
agency. Journal of Personality and Social Psychology, 71, 364374. https://doi.org/10.1037/0022-3514.71.2.364

Caravita, S., Di Blasio, P., \& Salmivalli, C. (2009). Unique and interactive effects of empathy and social status on involvement in bullying. Social Development, 18, 140-163. https://doi.org/10.1111/j. 1467-9507.2008.00465.x

Cohen, J. (1988). Statistical power analysis for the behavioral sciences. Erlbaum.

Cook, C. R., Williams, K. R., Guerra, N. G., Kim, T. E., \& Sadek, S. (2010). Predictors of bullying and victimization in childhood and adolescence: A meta-analytic investigation. School Psychology Quarterly, 25, 65-83. https://doi.org/10.1037/a0020149

Craig, W., Harel-Fisch, Y., Fogel-Grinvald, H., Dostaler, S., Hetland, J., Simons-Morton, B., Molcho, M., Gaspar de Mato, M., Overpeck, M., Due, P., Pickett, W., The HBSC Violence, Injuries Prevention Focus Group, \& HBSC Bullying Writing Group. (2009). A cross-national profile of bullying and victimization among adolescents in 40 countries. International Journal Public Health, 54 , 216-224. https://doi.org/10.1007/s00038-009-5413-9

Del Rey, R., Casas, J. A., Ortega-Ruiz, R., Schultze-Krumbholz, A., Scheithauer, H., Smith, P., Thompson, F., Barkoukis, V., Tsorbatzoudis, H., Brighi, A., Guarini, A., Pyzalsky, J., \& Plichta, P. (2015). Structural validation and cross-cultural robustness of the European Cyberbullying Intervention Project Questionnaire. Computers in Human Behavior, 50, 141-147. https://doi.org/10. 1016/j.chb.2015.03.065

Doumas, D., \& Midgett, A. (2020). The association between witnessing cyberbullying and depressive symptoms and social anxiety among elementary school students. Psychology in the Schools, 58, 622-637. https://doi.org/10.1002/pits.22467

Durlak, J. A., Weissberg, R. P., Dymnicki, A. B., Taylor, R. D., \& Schellinger, K. B. (2011). The impact of enhancing students' social and emotional learning: A meta-analysis of school-based universal interventions. Child Development, 82, 405-432. https:// doi.org/10.1111/j.1467-8624.2010.01564.x

Eden, S., Heiman, T., \& Olenik-Shemesh, D. (2016). Bully versus victim on the internet: The correlation with emotional-social characteristics. Education and Information Technologies, 21, 699-713. https://doi.org/10.1007/s10639-014-9348-2

Eslea, M., Menesini, E., Morita, Y., O’Moore, M., Mora-Merchan, J., Pereira, B., \& Smith, P. (2004). Friendship and loneliness among bullies and victims: Data from seven countries. Aggressive Behavior, 30, 71-83. https://doi.org/10.1002/ab.20006

Gaffney, H., Farrington, D. P., Espelage, D. L., \& Ttofi, M. M. (2019a). Are cyberbullying intervention and prevention programs effective? A systematic and meta-analytical review. Aggression and Violent Behavior, 45, 134-153. https://doi.org/10.1016/j.avb. 2018.07.002

Gaffney, H., Farrington, D. P., \& Ttofi, M. M. (2019b). Examining the effectiveness of school-bullying intervention programs globally: A meta-analysis. International Journal of Bullying Prevention, 1, 14-31. https://doi.org/10.1007/s42380-019-0007-4

Gaffney, H., Ttofi, M. M., \& Farrington, D. P. (2019c). Evaluating the effectiveness of school-bullying prevention programs: An updated meta-analytical review. Aggression and Violent Behavior, 45, 111-133. https://doi.org/10.1016/j.avb.2018.07.001

Gini, G., Pozzoli, T., \& Hymel, S. (2014). Moral disengagement among children and youth: A meta-analytic review of links to aggressive behavior. Aggressive Behavior, 40, 56-68. https://doi.org/10.1002/ ab. 21502

Heirman, W., \& Walrave, M. (2008). Assessing concerns and issues about the mediation of technology in cyberbullying. Cyberpsychology: Journal of Psychosocial Research on Cyberspace, 2. Retrieved from https://cyberpsychology.eu/article/view/4214/ 3256
Herrera-López, M., Casas, J. A., Romera, E. M., Ortega-Ruiz, R., \& Del Rey, R. (2017). Validation of the European Cyberbullying Intervention Project Questionnaire for Colombian adolescents. Cyberpsychology, Behavior, and Social Networking, 20, 117-125. https://doi.org/10.1089/cyber.2016.0414

Jolliffe, D., \& Farrington, D. P. (2006). Development and validation of the basic empathy scale. Journal of Adolescence, 29, 589-611. https://doi.org/10.1016/j.adolescence.2005.08.010

Kokkinos, C. M., \& Kipritsi, E. (2012). The relationship between bullying, victimization, trait emotional intelligence, self-efficacy and empathy among preadolescents. Social Psychology of Education, 15, 41-58. https://doi.org/10.1007/s11218-011-9168-9

Kowalski, R. M., Giumetti, G. W., Schroeder, A. N., \& Lattanner, M. R. (2014). Bullying in the digital age: A critical review and metaanalysis of cyberbullying research among youth. Psychological Bulletin, 140, 1073-1137. https://doi.org/10.1037/a0035618

Law, D. M., Shapka, J. D., \& Olson, B. F. (2010). To control or not to control? Parenting be-haviours and adolescent online aggression. Computers in Human Behavior, 26, 1651-1656. https:// doi.org/10.1016/j.chb.2010.06.013

Llorent, V. J., Farrington, D. P., \& Zych, I. (2021). School climate policy and its relations with social and emotional competencies, bullying and cyberbullying in secondary education. Revista De Psicodidáctica, 26, 35-44. https://doi.org/10.1016/j.psicoe. 2020.11.002

Lösel, F., \& Bender, D. (2011). Emotional and antisocial outcomes of bullying and victimization at school: A follow-up from childhood to adolescence. Journal of Aggression, Conflict and Peace Research, 3, 89-96. https://doi.org/10.1108/175965911111329 09

Marín-López, I., Zych, I., Ortega-Ruiz, R., Hunter, S. C., \& Llorent, V. J. (2020). Relations among online emotional content use, social and emotional competencies and cyberbullying. Children and Youth Services Review, 108, 104647. https://doi.org/10.1016/j. childyouth.2019.104647

Mikulic, I., Crespi, M., \& Radusky, P. (2015). Designing and Validation of Adult Socioemotional Competences Inventory (SECI). Interdisciplinaria, 32, 307-330. https://www.redalyc.org/pdf/180/ 18043528007.pdf

Monks, C. P., \& Smith, P. K. (2006). Definitions of bullying: Age differences in understanding of the term, and the role of experience. British Journal of Developmental Psychology, 24, 801-821. https://doi.org/10.1348/026151005X82352

Mora-Merchan, J. A., Ortega-Ruiz, R., Calmaestra, J., \& Smith, P. K. (2010). El uso violento de la tecnología: El cyberbullying. In R. Ortega (Ed.), Agresividad Injustificada, Bullying y Violencia Escolar (pp. 81-101). Alianza Editorial.

Nasaescu, E., Zych, I., Ortega-Ruiz, R., Farrington, D. P., \& Llorent, V. J. (2020). Longitudinal patterns of antisocial behaviors in early adolescence: A latent class and latent transition analysis. The European Journal of Psychology Applied to Legal Context, 12, 85-92. https://doi.org/10.5093/ejpalc2020a10

Oksanen, A., Miller, B. L., Savolainen, I., Sirola, A., Demant, J., Kaakinen, M., \& Zych, I. (2021). Social media and access to drugs online: A nationwide study in the United States and Spain among adolescents and young adults. European Journal of Psychology Applied to Legal Context, 13, 29-36. https://doi.org/10.5093/ejpal c2021a5

Ortega, R., Elipe, P., Mora-Merchán, J. A., Genta, M. L., Brighi, A., Guarini, A., Smith, P. K., Thompson, F., \& Tippett, N. (2012). The emotional impact of bullying and cyberbullying on victims: A European cross-national study. Aggressive Behavior, 38, 342-356. https://doi.org/10.1002/ab.21440

Ortega-Ruiz, R. (2010). Treinta años de investigación y prevalencia del bullying y la violencia escolar. In R. Ortega-Ruiz (Ed.), 
Agresividad Injustificada, Bullying y Violencia Escolar (pp. 13-15). Alianza Editorial.

Ortega-Ruiz, R., Del Rey, R., \& Casas, J. A. (2016). Evaluar el bullying y el cyberbullying validación española del EBIP-Q y del ECIPQ. Psicología Educativa, 22, 71-79. https://doi.org/10.1016/j.pse. 2016.01.004

Ortega-Ruiz, R., \& Monks, C. (2006). Violencia escolar y bullying. Información Psicológica, 87, 29-37.

Ortega-Ruiz, R., Sánchez, V., \& Menesini, E. (2002). Violencia entre iguales y desconexión moral: un análisis transcultural. Psicothema, 14, 37-49. https://www.researchgate.net/profile/Virginia_ Sanchez5/publication/277113112_Violencia_entre_iguales_y_ desconexion_moral_una_analisis_transcultural/links/5575d27808 aeb6d8c01ae5a4.pdf

Ozdemir, M., \& Stattin, H. (2011). Bullies, victims, and bully-victims: A longitudinal examination of the effects of bullying victimization experiences on youth well-being. Journal of Aggression, Conflict and Peace Research, 3, 97-102. https://doi.org/10.1108/17596 591111132918

Perren, S., \& Gutzwiller-Helfenfinger, E. (2012). Cyberbullying and traditional bullying in adolescence: Differential roles of moral disengagement, moral emotions, and moral values. European Journal of Developmental Psychology, 9, 195-209. https://doi. org/10.1080/17405629.2011.643168

Raskauskas, J. L., Gregory, J., Harvey, S. T., Rifshana, F., \& Evans, I. M. (2010). Bullying among primary school children in New Zealand: Relationships with prosocial behavior and classroom climate. Educational Research, 52, 1-13. https://doi.org/10.1080/ 00131881003588097

Romera, E. M., Casas, J. A., Gómez-Ortiz, O., \& Ortega-Ruiz, R. (2019). Moral domain as a risk and protective factor against bullying. An integrating perspective review on the complexity of morality. Aggression and Violent Behavior, 45, 75-82. https://doi. org/10.1016/j.avb.2018.07.005

Romera, E., Ortega, R., Del Rey, R., Casas, J. A., Viejo, C., Gómez, O., \& Luque, R. (2017). Bullying, cyberbullying y dating violence. Estudio de la gestión de la Vida social en estudiantes de Primaria y Secundaria de Andalucía. Colección Actualidad, 75.

Saarni, C. (1999). The development of emotional competence. Guilford.

Shakoor, S., Jaffee, S. R., Andreou, P., Bowes, L., Ambler, A. P., Caspi, A., et al. (2011). Mothers and children as informants of bullying victimization: Results from an epidemiological cohort of children. Journal of Abnormal Child Psychology, 39, 379-387. https://doi. org/10.1007/s10802-010-9463-5

Smith, P., Mahdavi, J., Carvalho, M., Fisher, S., Russell, S., \& Tippet, N. (2008). Cyberbullying: Its nature and impact in secondary school pupils. The Journal of Child Psychology and Psychiatry, 49, 376-385. https://doi.org/10.1111/j.1469-7610.2007.01846.x

Sorrentino, A., Baldry, A. C., Farrington, D. P., \& Blaya, C. (2019). Epidemiology of Cyberbullying across Europe: Differences between Countries and Genders. Educational Sciences: Theory and Practice, 19, 74-91. https://doi.org/10.12738/estp.2019.2.005

Sticca, F., Ruggieri, S., Alsaker, F., \& Perren, S. (2013). Longitudinal risk factors for cyberbullying in adolescence. Journal of Community and Applied Social Psychology, 23, 52-67. https://doi.org/ 10.1002/casp.2136

Sutton, J., Smith, P. K., \& Swettenham, J. (1999). Social cognition and bullying: Social inadequacy or skilled manipulation? British Journal of Developmental Psychology, 17, 435-450. https://doi. org/10.1348/026151099165384

Troop-Gordon, W. (2017). Peer victimization in adolescence: The nature, progression, and consequences of being bullied within a developmental context. Journal of Adolescence, 55, 116-128. https://doi.org/10.1016/j.adolescence.2016.12.012
Ttofi, M. M., \& Farrington, D. P. (2011). Effectiveness of school-based programs to reduce bullying: A systematic and meta-analytic review. Journal of Experimental Criminology, 7, 27-56. https:// doi.org/10.1007/s11292-010-9109-1

Ttofi, M. M., Farrington, D. P., \& Lösel, F. (2011). Health consequences of school bullying. Journal of Aggression, Conflict and Peace Research, 3, 60-62. https://doi.org/10.1108/jacpr.2011. 55003baa.002

Twardowska-Staszek, E., Zych, I., \& Ortega-Ruiz, R. (2018). Bullying and cyberbullying in Polish elementary and middle schools: Validation of questionnaires and nature of the phenomena. Children and Youth Services Review, 95, 217-225. https://doi.org/10. 1016/j.childyouth.2018.10.045

Van Geel, M., Vedder, P., \& Tanilon, J. (2014). Relationship between peer victimization, cyberbullying, and suicide in children and adolescents a meta-analysis. Jama Pediatrics, 168, 435-442. https:// doi.org/10.1001/jamapediatrics.2013.4143

Yuchang, J., Junyi, L., Junxiu, A., Jing, W., \& Mingcheng, H. (2017). The Differential victimization associated with depression and anxiety in cross-cultural perspective: A Meta-Analysis. Trauma, Violence and Abuse, 20, 560-573. https://doi.org/10.1177/15248 38017726426

Zych, I., Baldry, A. C., Farrington, D. P., \& Llorent, V. J. (2019a). Are children involved in cyberbullying low on empathy? A systematic review and meta-analysis of research on empathy versus different cyberbullying roles. Aggression and Violent Behavior, 45, 83-97. https://doi.org/10.1016/j.avb.2018.03.004

Zych, I. \& Farrington, D. P. (2021). Stability and change in bullying and cyberbullying throughout the school years. In: Smith P. K., O`Higgins Norman J., \& Sciacca B. (eds.), The Wiley Blackwell Handbook of Bullying, Wiley Blackwell.

Zych, I., Farrington, D. P., Jolliffe, D., \& Twardowska-Staszek, E. (2021). Empathy in Polish and Spanish children and adolescents. Validation of the basic empathy scale and its relation to bullying, cyberbullying, and other antisocial behaviours. In D. Jolliffe \& D. P. Farrington (Eds.), Empathy versus offending, aggression and bullying: Advancing knowledge using the basic empathy scale (pp. 188-199). Routledge.

Zych, I., \& Llorent, V. J. (2019). Affective empathy and moral disengagement related to late adolescent bullying perpetration. Ethics and Behavior, 29, 547-556. https://doi.org/10.1080/10508422. 2018.1521282

Zych, I., Ortega-Ruiz, R., \& Llorent, V. J. (2017). Nature and dynamics of peer violence in Polish upper secondary schools. Social Psychology of Education, 20, 427-443. https://doi.org/10.1007/ s11218-017-9378-x

Zych, I., Ortega-Ruiz, R., \& Marín-López, I. (2016). Cyberbullying: A systematic review of research, its prevalence and assessment issues in Spanish studies. Psicología Educativa, 22, 5-18. https:// doi.org/10.1016/j.pse.2016.03.002

Zych, I., Ortega-Ruiz, R., Muñoz-Morales, R., \& Llorent, V. J. (2018). Dimensiones y Propiedades Psicométricas del Cuestionario de Competencias Sociales y Emocionales (SEC-Q) en jóvenes y adolescentes. Revista Latinoamericana De Psicología, 50, 98-106. https://doi.org/10.14349/rlp.2018.v50.n2.3

Zych, I., Ttofi, M. M., \& Farrington, D. P. (2019b). Empathy and callous-unemotional traits in different bullying roles: A systematic review and meta-analysis. Trauma, Violence, and Abuse, 20, 3-21. https://doi.org/10.1177/1524838016683456

Publisher's Note Springer Nature remains neutral with regard to jurisdictional claims in published maps and institutional affiliations. 